\title{
Evaluating preferences for profiles of glucagon-like peptide-I receptor agonists among injection-naive type 2 diabetes patients in Japan
}

This article was published in the following Dove Press journal:

Patient Preference and Adherence

25 July 2016

Number of times this article has been viewed

\author{
Heather L Gelhorn' \\ Elizabeth D Bacci \\ Jiat Ling Poon' \\ Kristina S Boye ${ }^{3}$ \\ Shuichi Suzuki ${ }^{4}$ \\ Steven M Babineaux ${ }^{3}$ \\ 'Outcomes Research, Evidera, \\ Bethesda, MD, ${ }^{2}$ Evidera, Seattle, \\ WA, ${ }^{3}$ Global Patient Outcomes and \\ Real World Evidence, Eli Lilly and \\ Company, Indianapolis, IN, USA: \\ ${ }^{4}$ Medicines Development Unit Japan, \\ Eli Lilly Japan, Kobe, Japan
}

Objective: The objective of this study was to use a discrete choice experiment (DCE) to estimate patients' preferences for the treatment features, safety, and efficacy of two specific glucagon-like peptide-1 receptor agonists, dulaglutide and liraglutide, among patients with type 2 diabetes mellitus (T2DM) in Japan.

Methods: In Japan, patients with self-reported T2DM and naive to treatment with self-injectable medications were administered a DCE through an in-person interview. The DCE examined the following six attributes of T2DM treatment, each described by two levels: "dosing frequency", "hemoglobin A1c change", "weight change", "type of delivery system", "frequency of nausea", and "frequency of hypoglycemia". Part-worth utilities were estimated using logit models and were used to calculate the relative importance (RI) of each attribute. A chi-square test was used to determine the differences in preferences for the dulaglutide versus liraglutide profiles.

Results: The final evaluable sample consisted of 182 participants (mean age: 58.9 [standard deviation $=10.0$ ] years; $64.3 \%$ male; mean body mass index: 26.1 [standard deviation $=5.0$ ] kg/m $\mathrm{m}^{2}$ ). The RI values for the attributes in rank order were dosing frequency (44.1\%), type of delivery system $(26.3 \%)$, frequency of nausea $(15.1 \%)$, frequency of hypoglycemia $(7.4 \%)$, weight change $(6.2 \%)$, and hemoglobin A1c change (1.0\%). Significantly more participants preferred the dulaglutide profile $(94.5 \%)$ compared to the liraglutide profile $(5.5 \% ; P<0.0001)$.

Conclusion: This study elicited the preferences of Japanese T2DM patients for attributes and levels representing the actual characteristics of two existing glucagon-like peptide-1 receptor agonists. In this comparison, dosing frequency and type of delivery system were the two most important characteristics, accounting for $>70 \%$ of the RI. These findings are similar to those of a previous UK study, providing information about patients' preferences that may be informative for patient-clinician treatment discussions.

Keywords: discrete choice experiment, patient's preference, type 2 diabetes, GLP-1 receptor agonists, willingness to inject

\section{Introduction}

Diabetes is one of the most common noncommunicable diseases, with an estimated global prevalence of 8.8\% among people aged 20-79 years in $2015 .{ }^{1}$ In Japan, there were an estimated 7.2 million cases of diabetes in 2015 , with a $7.6 \%$ prevalence among adults aged 20-79 years. ${ }^{1}$ Type 2 diabetes mellitus (T2DM) is the most common form of diabetes, and the goal of managing T2DM is to maintain blood glucose levels within acceptable limits. Japanese guidelines for the management of T2DM recommend beginning with lifestyle modifications such as diet and exercise therapy, before progressing to oral T2DM drugs and/or injectable therapy if target glycemic control
Correspondence: Heather L Gelhorn Evidera, 7I0I Wisconsin Avenue, Suite 1400, Bethesda, MD 208I4, USA

$\mathrm{Tel}+\mathrm{I} 3032162274$

Fax +I 30327 I 3665

Email heather.gelhorn@evidera.com 
is not achieved. ${ }^{2}$ Injectable therapies may include insulin or other options such as glucagon-like peptide-1 (GLP-1) receptor agonists (RA).

GLP-1 RA have demonstrated efficacy in lowering hemoglobin A1c (HbA1c) and weight, while minimizing the risk of hypoglycemia. ${ }^{3}$ All GLP-1 RA are administered as a subcutaneous injection, and while all have demonstrated efficacy in reducing $\mathrm{HbA} 1 \mathrm{c}$, differences exist between the available treatments in terms of magnitude of $\mathrm{HbAlc}$ lowering, effect on weight, frequency of administration, and frequency and severity of adverse effects such as nausea and hypoglycemia. ${ }^{3}$ As of September 2015, there were five GLP-1 RA approved for use in Japan, ${ }^{4}$ including liraglutide, exenatide, exenatide once weekly, lixisenatide, and dulaglutide. For this study, dulaglutide and liraglutide were compared because data from a head-to-head clinical trial were available to directly determine the levels of the attributes for these two medications.

With demonstrated differences between available GLP-1 RA, it is important to understand patients' preferences for the clinical and nonclinical features of this class of compounds and the factors influencing these preferences, in order to inform treatment selection. To do so, a discrete choice experiment (DCE) was conducted among patients with T2DM in Japan to compare features of GLP-1 RA, specifically dulaglutide and liraglutide.

In a DCE, participants are presented with hypothetical medication choices and asked to select their preferred option in a decision-making approach that closely resembles the way individuals make decisions on a daily basis. This allows for the determination of the relative importance (RI) of different features of the medications in determining the overall value of a treatment. The DCE methodology has previously been used in a Japanese population in the context of health care and/or the provision of health services to examine patient preferences for anticoagulant treatments in atrial fibrillation, ${ }^{5}$ pharmacist counseling in breast cancer, ${ }^{6}$ and intermittent urinary catheters in neurogenic bladder. ${ }^{7}$

To date, no known published DCEs have been conducted in a Japanese population in the therapeutic area of T2DM. However, several prior studies in other countries have examined medication preferences among patients with T2DM, typically focusing on specific aspects of T2DM treatments. Previous studies have compared patients' general preferences for the overall features of medications such as glucose reduction, dosing frequency, frequency of hypoglycemia, weight change, cost, and risk of other adverse effects such as gastrointestinal side effects, genital infection, and cardiovascular side effects. ${ }^{8-10}$ In this group of studies, where the full range of each product's characteristic was examined (ie, efficacy and weight change that ranged widely across medication options), the clinical features of T2DM treatments such as frequency of hypoglycemia and $\mathrm{HbA} 1 \mathrm{c}$ reduction were generally identified as being of greatest importance to patients. Another previous study examined patients' preferences for features of GLP-1 RA, ${ }^{11}$ examining injection-related features such as type of injection device, needle size and pain, injection frequency, refrigeration, and injection site reactions. Among these injection-related features, the frequency of injection was found to be of greatest importance to patients.

In addition to these prior studies, which focused on comparing the general characteristics of T2DM treatments, DCEs can also be designed to specifically examine the RI of medication characteristics that reflect the actual differences between existing medications. ${ }^{12}$ This may be of particular importance when comparing medications with highly similar efficacy or side effect profiles but differing in other nonclinical factors such as dosing frequency and type of delivery system. In a DCE of UK patients with T2DM preferences for features of GLP-1 RA informed by features drawn directly from a head-to-head comparison of dulaglutide and liraglutide in a clinical trial, it was observed that when differences in clinical factors such as HbAlc change, weight change, frequency of nausea, and frequency of hypoglycemia between medication options were small, nonclinical factors such as dosing frequency and type of delivery system assumed greater importance in influencing patient preferences for treatment options. ${ }^{12}$ Understanding patient preferences for these nonclinical factors may help guide patient-clinician treatment discussions and selection. In particular, when the treatment options that are available to patients are highly similar in terms of clinical characteristics, it is of interest to determine whether the RI of these attributes remains high in circumstances when they do little to differentiate the products of interest.

As a follow-up to the work conducted among UK patients with $\mathrm{T} 2 \mathrm{DM},{ }^{12}$ the primary objective of this study was to use a DCE to characterize Japanese patients' preferences for medication attributes specifically in the context of a comparison of the dulaglutide and liraglutide profiles. This study was modeled after the prior UK study but differed in that the medication features selected for the DCE were specific to the Japanese T2DM population and the patients were recruited through slightly different procedures. Additionally, the results from a clinical trial comparing dulaglutide $0.75 \mathrm{mg}$ (once weekly) and liraglutide $0.9 \mathrm{mg}$ (once daily) 
were used to inform the specification of the attribute levels for this study, ${ }^{13}$ reflecting the actual observed differences between the two products of interest in the target patient population and the approved doses of the two products in Japan. As it is unclear the extent to which the results from discrete choice studies are consistent or generalizable across different countries and cultures, this study was also aimed at exploring whether patient preferences for these product attributes were markedly different in Japan. Secondary objectives were to determine Japanese patients' preferences for medication profiles representing dulaglutide versus liraglutide and willingness to self-inject medication for the treatment of T2DM.

\section{Methods DCE design}

The DCE design of this study was a replication of that used in the previous UK DCE investigation. ${ }^{12}$ Thus, the same attributes were selected for the study as were used in the UK. These attributes were originally selected based on a review of attributes commonly used in other studies of T2DM medications $^{8,14}$ (ie, efficacy, weight change, hypoglycemia, and nausea), and those that were judged to be relevant to a comparison of dulaglutide and liraglutide (ie, dosing frequency and type of delivery system). ${ }^{12}$ Six attributes were included, which was consistent with other previously published DCE studies that routinely utilize between three and seven attributes ${ }^{15}$ (Table 1). The DCE task involved presenting participants with medication choices (ie, choice pairs). Each choice included two hypothetical medication profiles comprised of all six attributes, with each medication described by a specific level for every attribute. For example, in one choice, both medications may have had the same dosing frequency and weight change but varied in the levels for each of the other attributes. The experimental design was developed using Statistical Analysis System (SAS) statistical software based on a D-efficiency criterion. ${ }^{16}$ A priori, it was expected that participants would prefer less frequent dosing, a greater percentage of patients reaching their at $\mathrm{HbA1c}$ goal, greater weight loss, less nausea, and less frequent hypoglycemia.

The levels for each of the attributes were based on the results of only the Japanese-specific clinical trial, which compared dulaglutide $0.75 \mathrm{mg}$ (once weekly) and liraglutide $0.9 \mathrm{mg}$ (once daily). ${ }^{13}$ The attributes and levels were tested in a pilot study ( $n=40)$; however, no changes to the wording of the instructions to the DCE or attributes and levels were needed.

Sample size was estimated using the number of choice pairs (eight) included in the DCE analysis, number of alternatives (two) per choice pair, and maximum number of levels (two) for any one attribute. Based on these study parameters, a sample size of 200 patients was targeted. This sample size was informed by the results of the previous research and allowed for a sufficient number of participants for the planned subgroup analyses. ${ }^{17}$ The choice sets were developed using SAS Version 9.4 based on a D-efficiency criterion.

\section{Participants}

Participants were recruited by a patient recruitment organization in Japan (CROee Inc., Tokyo, Japan) that maintains Japan's largest online database of volunteers for clinical research. To recruit participants, advertisements viewable only to volunteers belonging to the database were placed on the recruitment website maintained by the patient recruitment organization. Interested participants who responded to the advertisement were screened via telephone

Table I Attributes and levels for the discrete choice experiment

\begin{tabular}{|c|c|}
\hline Attributes & Levels \\
\hline Dosing frequency & $\begin{array}{l}\text { - Once a week (52 times per year). }{ }^{\mathrm{a}} \\
\text { - Once a day (365 times per year). }{ }^{\mathrm{b}}\end{array}$ \\
\hline $\begin{array}{l}\text { Blood sugar }(\mathrm{HbAlc}) \\
\text { change }\end{array}$ & $\begin{array}{l}\text { - } 71.4 \% \text { of patients taking the medication reach their desired blood sugar (HbAlc) goals of }<7 \%{ }^{a} \\
\text { - } 69.1 \% \text { of patients taking the medication reach their desired blood sugar (HbAlc) goals of }<7 \% \text {. }^{\text {b }}\end{array}$ \\
\hline Weight change & $\begin{array}{l}\text { - On average, patients experience a very small amount of weight loss }(-0.36 \mathrm{~kg}) .^{\mathrm{b}} \\
\text { - On average, patients do not experience any change in their body weight. }{ }^{\mathrm{a}}\end{array}$ \\
\hline Type of delivery system & $\begin{array}{l}\text { - Single-use prefilled pen ready for injection. }{ }^{\mathrm{a}} \\
\text { - Multidose prefilled pen, used with disposable injection needles, dosage selection required. }\end{array}$ \\
\hline Frequency of nausea & $\begin{array}{l}\text { - } 5.4 \% \text { of patients experience nausea anytime in the first } 6 \text { months of treatment. }{ }^{a} \\
\text { - } 8.0 \% \text { of patients experience nausea anytime in the first } 6 \text { months of treatment. }\end{array}$ \\
\hline $\begin{array}{l}\text { Frequency of low blood } \\
\text { sugar event (hypoglycemia) }\end{array}$ & $\begin{array}{l}\text { - } 1.5 \% \text { of patients experience a low blood sugar (hypoglycemic) event in the first } 6 \text { months of treatment. } \\
\text { - } 2.1 \% \text { of patients experience a low blood sugar (hypoglycemic) event in the first } 6 \text { months of treatment. }\end{array}$ \\
\hline
\end{tabular}

Notes: aLevel representing dulaglutide. 'Level representing liraglutide.

Abbreviation: $\mathrm{HbAlc}$, hemoglobin Alc. 
to assess eligibility. The following eligibility criteria were used: male or female $\geq 20$ years of age, diagnosed with T2DM, taking at least one oral T2DM medication, able to read and understand Japanese, and willing and able to provide written informed consent. Participants were excluded from study participation if they met any of the following criteria: if they had a cognitive impairment, hearing difficulty, visual impairment, severe psychopathology, or insufficient knowledge of the Japanese language that could interfere with their ability to provide written consent; unable to write in Japanese; diagnosed with type 1 diabetes or gestational diabetes; T2DM that is currently treated only with diet and exercise; previously been treated with a self-injectable medication for any medical condition including T2DM; previously administered an injectable medication to another person for any medical condition including T2DM; or was a pharmaceutical employee or employed in a position where they had a direct role in treating patients with diabetes.

In order to confirm a diabetes diagnosis, participants brought their medication notebook to the interview or described their diagnosis process. The medication notebook is created and updated by the pharmacist when the patient fills a prescription and includes all of the medication information for the patient. All participants provided written informed consent prior to participating in the study, and the study protocol was approved by an independent ethical review board (Ethical and Independent Review Services LLC - Independence, MO, USA: August 1, 2015).

\section{Study procedures}

The pilot study was conducted to assess the comprehensibility of the DCE study description, relevance of the study attributes to the participant's T2DM, and the burden of completing the study tasks. Individual interview sessions were led by trained moderators; participants self-completed the survey and a sociodemographic and clinical information questionnaire.

For both the pilot study (August-September 2015) and the main study (September-October 2015), the survey consisted of five sections administered in the following order: 1) a question determining participants' willingness to self-inject medication for T2DM; 2) a description of the DCE portion of the study, which indicated to the participants that they would be presented with pairs of hypothetical medications and would be asked which of the medications they preferred; 3) the DCE choice task, where participants reviewed the descriptions of all the medication attributes and levels, as well as watched two videos that demonstrated the use of devices representing those that are available in Japan for administration of dulaglutide and liraglutide, respectively; ${ }^{18,19} 4$ ) two questions asking about participants' willingness to self-inject a product with profiles representing dulaglutide and liraglutide, respectively; and 5) a sociodemographic and clinical information questionnaire. The order of presentation of the videos describing the devices was varied using a block design, and the content of the videos was obtained from the Japanese-specific instructions for documentation of each drug. No product names were mentioned anywhere in the videos or survey.

More specifically, the DCE consisted of choices between two hypothetical medications (ie, choice pairs), each described by one level for each of the six attributes (Table 1). For each of ten medication choice pairs, participants were asked to indicate which medication they preferred. One of the ten choice pairs presented to each participant was a fixed choice with one clearly correct option (in comparison to the other nine choice pairs where there was no right or wrong answer). The fixed choice was used to ensure that participants understood the discrete choice format and attended appropriately to the task. Any participants who responded incorrectly to the fixed choice question were excluded from the analysis. Additionally, one of the medication choices presented the medication profiles for dulaglutide and liraglutide, respectively. This choice was embedded within the DCE design and was indistinguishable to participants from the other DCE choices. Participants' responses to this question were used to determine their direct preference for the dulaglutide profile compared to the liraglutide profile but were not used in estimating the results of the DCE.

\section{Analyses}

Data from the pilot and main study were pooled for the analyses; this decision was made a priori. SAS ${ }^{\circledR}$ statistical software Version 9.4 (SAS Institute Inc., Cary, NC, USA) was used to conduct the analyses. Descriptive statistics (frequencies, mean values, and standard deviations [SDs]) were reported for sociodemographic and self-reported clinical variables (Table 2) and for questions on willingness to use injectable medications and willingness to use medications represented by the dulaglutide and liraglutide profiles. The DCE responses were analyzed using a logit regression model. ${ }^{16}$

For the DCE analysis, part-worth utility estimates (ie, the regression coefficients, Table 3 ) were computed for the overall sample and by age and sex subgroups. Part-worth utility values (or preference weights) provide information on the extent to which participants prefer each level of an attribute 
Table 2 Self-reported sociodemographic and clinical characteristics

\begin{tabular}{|c|c|c|c|}
\hline & $\begin{array}{l}\text { Overall sample } \\
(\mathrm{N}=182)\end{array}$ & $\begin{array}{l}\text { Pilot sample } \\
(\mathbf{N}=37)\end{array}$ & $\begin{array}{l}\text { Main sample } \\
(\mathrm{N}=\mid 45)\end{array}$ \\
\hline \multicolumn{4}{|l|}{ Sex, n (\%) } \\
\hline Male & $117(64.3)$ & $27(73.0)$ & $90(62.1)$ \\
\hline Female & $65(35.7)$ & $10(27.0)$ & $55(37.9)$ \\
\hline Age (years), mean (SD) [range] & $58.9(10.0)[32-81]$ & $56.2(9.4)[33-7 I]$ & $59.5(10.1)[32-8 \mid]$ \\
\hline \multicolumn{4}{|l|}{ Age group (years), n (\%) } \\
\hline $30-39$ & $4(2.2)$ & I (2.7) & $3(2.1)$ \\
\hline $40-49$ & $27(\mid 4.8)$ & $7(18.9)$ & $20(13.8)$ \\
\hline $50-59$ & $64(35.2)$ & $15(40.5)$ & $49(33.8)$ \\
\hline $60-69$ & $61(33.5)$ & II (29.7) & $50(34.5)$ \\
\hline $70+$ & $26(14.3)$ & $3(8.1)$ & $23(15.9)$ \\
\hline \multicolumn{4}{|l|}{ Education, n (\%) } \\
\hline Middle school graduate & $7(3.9)$ & $2(5.4)$ & $5(3.5)$ \\
\hline High school graduate & $66(36.5)$ & $13(35.1)$ & $53(36.8)$ \\
\hline Vocational/work-based qualifications, partial college & $35(19.3)$ & 7 (I8.9) & $28(19.4)$ \\
\hline University degree & $72(39.8)$ & $14(37.8)$ & $58(40.3)$ \\
\hline Postgraduate degree & $\mathrm{I}(0.6)$ & I (2.7) & $0(0.0)$ \\
\hline \multicolumn{4}{|l|}{ Household income, n (\%) } \\
\hline$<\mathrm{I}$ million yen & $5(2.8)$ & $0(0.0)$ & $5(3.5)$ \\
\hline I million yen to $<2$ million yen & $14(7.7)$ & $2(5.4)$ & $12(8.3)$ \\
\hline 2 million yen to $<4$ million yen & $30(16.5)$ & $9(24.3)$ & $21(14.5)$ \\
\hline 4 million yen to $<6$ million yen & $28(15.4)$ & $2(5.4)$ & $26(17.9)$ \\
\hline 6 million yen to $<10$ million yen & $43(23.6)$ & $9(24.3)$ & $34(23.5)$ \\
\hline 10 million yen to $<15$ million yen & $4(2.2)$ & $\mathrm{I}(2.7)$ & $3(2.1)$ \\
\hline Missing & $58(31.9)$ & $14(37.8)$ & $44(30.3)$ \\
\hline Height $(\mathrm{cm})$, mean $(\mathrm{SD})$ [range] & $164.3(9.2)[143-185]$ & $167.2(8.0)[148-185]$ & I $63.5(9.4)[143-185]$ \\
\hline Weight (kg), mean (SD) [range] & $70.5(15.0)[37-150]$ & $72.8(13.1)[53-110]$ & $70.0(15.4)[37-150]$ \\
\hline BMI $\left(\mathrm{kg} / \mathrm{m}^{2}\right)$, mean $(\mathrm{SD})$ [range] & $26.1(5.0)[16-58]$ & $26.0(3.8)[20-35]$ & $26.1(5.3)[16-58]$ \\
\hline \multicolumn{4}{|l|}{ Duration of type 2 diabetes mellitus, $n$ (\%) } \\
\hline$<\mathrm{I}$ year & $7(3.9)$ & $3(8.1)$ & $4(2.8)$ \\
\hline$>1$ year and up to 5 years & $59(32.4)$ & $14(37.8)$ & $45(31.0)$ \\
\hline$>5$ years and up to 10 years & $53(29.1)$ & $9(24.3)$ & $44(30.3)$ \\
\hline$>10$ years & $63(34.6)$ & II (29.7) & $52(35.9)$ \\
\hline \multicolumn{4}{|l|}{ Current type 2 diabetes mellitus treatment, $\mathrm{n}(\%)$} \\
\hline One oral diabetes medication only & $77(42.3)$ & $16(43.2)$ & $61(42.1)$ \\
\hline Two oral diabetes medication only & $62(34.1)$ & $14(37.8)$ & $48(33.1)$ \\
\hline Three or more oral diabetes medication & $43(23.6)$ & $7(18.9)$ & $36(24.8)$ \\
\hline \multicolumn{4}{|l|}{ Current HbAlc level, n (\%) } \\
\hline Below $53 \mathrm{mmol} / \mathrm{mol}(<7 \%)$ & $97(53.3)$ & $19(51.4)$ & $78(53.8)$ \\
\hline Between $54 \mathrm{mmol} / \mathrm{mol}$ and $64 \mathrm{mmol} / \mathrm{mol}$ (between $7.1 \%$ and $8 \%$ ) & $57(31.3)$ & $10(27.0)$ & $47(32.4)$ \\
\hline Between $65 \mathrm{mmol} / \mathrm{mol}$ and $75 \mathrm{mmol} / \mathrm{mol}$ (between $8.1 \%$ and $9 \%$ ) & $16(8.8)$ & $4(10.8)$ & $12(8.3)$ \\
\hline$>75 \mathrm{mmol} / \mathrm{mol}(>9 \%)$ & $12(6.6)$ & $4(10.8)$ & $8(5.5)$ \\
\hline I don't know & $0(0.0)$ & $0(0.0)$ & $0(0.0)$ \\
\hline
\end{tabular}

Abbreviations: BMI, body mass index; HbAlc, hemoglobin Alc.

and were scaled within each attribute to have a mean of 0 . Larger part-worth utility values indicate a higher degree of preference. A positive value indicates that the attribute level is preferred, while negative values indicate a preference for other levels of the attribute.

The RI of each attribute was calculated by summing the range of part-worth utility values for all attributes (ie, the largest minus the smallest part-worth utility values within each attribute), yielding the overall utility value, and then by dividing each individual attribute's utility range by the overall utility value (example calculation in Table 3$) \cdot{ }^{17}$ The RI of each attribute is expressed as a percentage and reflects the proportion of the variance in the overall medication decision that is accounted for by each attribute.

Logit regression models with interaction effects were also used to test for significant differences in preferences for the levels of each attribute across sex and age ( $<60$ years vs $\geq 60$ years) subgroups. Chi-square tests were used to 
Table 3 Part-worth utilities, relative importance, and rankings of attributes in overall sample

\begin{tabular}{|c|c|c|c|c|c|c|}
\hline Parameter & Attribute levels & $\begin{array}{l}\text { Part-worth utility } \\
\text { estimate (SE) }\end{array}$ & $P$-value ${ }^{b}$ & $\begin{array}{l}\text { Overall part-worth } \\
\text { utility value }^{c}\end{array}$ & $\begin{array}{l}\text { Relative } \\
\text { importance }^{d}(\%)\end{array}$ & Rank \\
\hline \multirow[t]{2}{*}{ Dosing frequency } & Once a day (365 times per year) & $-1.236(0.101)$ & $<0.0001$ & \multirow{2}{*}{2.47} & \multirow{2}{*}{44.1} & \multirow{2}{*}{ I } \\
\hline & Once a week (52 times per year) & $1.236(0.101)$ & $<0.0001$ & & & \\
\hline \multirow[t]{2}{*}{ Type of delivery system } & Multidose prefilled pen & $-0.739(0.091)$ & $<0.0001$ & \multirow{2}{*}{1.48} & \multirow{2}{*}{26.3} & \multirow{2}{*}{2} \\
\hline & Single-use prefilled pen & $0.739(0.091)$ & $<0.0001$ & & & \\
\hline \multirow[t]{2}{*}{ Frequency of nausea } & $8.0 \%$ experience nausea & $-0.423(0.062)$ & $<0.0001$ & \multirow{2}{*}{0.85} & \multirow{2}{*}{15.1} & \multirow{2}{*}{3} \\
\hline & $5.4 \%$ experience nausea & $0.423(0.062)$ & $<0.0001$ & & & \\
\hline \multirow{2}{*}{$\begin{array}{l}\text { Frequency of low blood } \\
\text { sugar events (hypoglycemia) }\end{array}$} & Once every 2 years & $-0.206(0.049)$ & $<0.0001$ & \multirow[b]{2}{*}{$0.4 I$} & \multirow[b]{2}{*}{7.4} & \multirow[b]{2}{*}{4} \\
\hline & Once every 3 years & $0.206(0.049)$ & $<0.0001$ & & & \\
\hline \multirow[t]{2}{*}{ Weight change } & $0 \mathrm{~kg}$ weight loss & $-0.173(0.049)$ & 0.0004 & \multirow{2}{*}{0.35} & \multirow{2}{*}{6.2} & \multirow{2}{*}{5} \\
\hline & $0.36 \mathrm{~kg}$ weight loss & $0.173(0.049)$ & 0.0004 & & & \\
\hline \multirow[t]{2}{*}{ Blood sugar ( $\mathrm{HbAlc})$ change } & $69.1 \%$ at goal & $-0.028(0.046)$ & 0.5502 & \multirow{2}{*}{0.06} & \multirow{2}{*}{1.0} & \multirow{2}{*}{6} \\
\hline & $71.4 \%$ at goal & $0.028(0.046)$ & 0.5502 & & & \\
\hline
\end{tabular}

Notes: aPart-worth utility values provide information on the extent to which participants prefer each level of an attribute and are scaled within each attribute to have a mean of 0 . A positive part-worth utility value indicates that the attribute level is preferred, while negative values indicate a preference for other levels of the attribute. ${ }^{b}$ The $P$-values indicate whether the part-worth utility value differs significantly from $0 .{ }^{~}$ The overall utility values represent the range of utility values within each attribute. ${ }^{d}$ Relative importance for each attribute $=\frac{\text { Overall utility value for each attribute }}{\text { Tota }}$,

Abbreviations: SE, standard error; HbAlc, hemoglobin Alc. Total utility value

determine whether there were significant differences in the $\mathrm{RI}$ of the attributes across age and sex subgroups, as well to test for significant differences in the direct preference for dulaglutide or liraglutide medication profiles.

\section{Results}

\section{Sample characteristics}

A total of 200 participants completed the survey. Eighteen participants $(9.0 \%)$ were excluded from the final analytic sample because these participants provided an incorrect response on the fixed choice question, resulting in a final analysis sample of 182 participants. The participant demographic and self-reported clinical characteristics are presented in Table 2. A majority of the sample was male $(64.3 \%)$, with a mean age of $58.9(\mathrm{SD}=10.0)$ years and mean body mass index of 26.1 ( $\mathrm{SD}=5.0$ ). For the majority of the sample, current $\mathrm{HbA} 1 \mathrm{c}$ levels were $<53 \mathrm{mmol} / \mathrm{mol}(53.3 \%)$ or between $54 \mathrm{mmol} / \mathrm{mol}$ and $64 \mathrm{mmol} / \mathrm{mol}(31.3 \%)$.

\section{Results of the DCE}

\section{Patient preferences in the overall sample}

In the overall sample, the results of the DCE indicated that the most important attribute was "dosing frequency" ( $\mathrm{RI}=44.1 \%$ ), followed by the "type of delivery system" ( $\mathrm{RI}=26.3 \%$; Table 3). The RI of the remaining attributes was lower, including "frequency of nausea" (RI $=15.1 \%$ ), "frequency of hypoglycemia" (RI =7.4\%), "weight change" $(\mathrm{RI}=6.2 \%)$, and "HbA1c change" ( $\mathrm{RI}=1.0 \%)$. All comparisons between levels of each attribute were statistically significant (all $P<0.001$ ) except "blood sugar (HbA1c) change".
Consistent with the a priori hypotheses, the results reflected preferences in the expected direction for each of the attributes (Table 3; Figure 1). Participants also indicated a preference toward the single-use prefilled pen delivery system.

\section{Patient preferences by sex}

Subgroup analyses were conducted to examine participant preferences by sex (Figure 2). The attributes with the highest RI for both males and females were dosing frequency (males: $\mathrm{RI}=48.2 \%$ and female: $\mathrm{RI}=35.7 \%$ ) and type of delivery system (males: $\mathrm{RI}=23.1 \%$ and females $\mathrm{RI}=32.1 \%$ ). The attributes with significantly different $\mathrm{RI}$ between sexes were dosing frequency $(P<0.001)$ and frequency of low blood sugar events $(P<0.03)$, both of these attributes were more important to males. For both males and females, significant preferences were observed across the levels of all attributes except for $\mathrm{HbA} 1 \mathrm{c}$ change. Both males and females had a preference for once a week versus once a day dosing frequency; however, this preference was significantly stronger among males $(P<0.05)$.

\section{Patient preferences by age group}

Patient preferences for T2DM treatment attributes were also examined separately by age groups, using the distribution of the sample to select the age threshold cutoff (ie, $<60$ years vs $\geq 60$ years of age; Figure 3 ). Again, dosing frequency ( $<60$ years: $\mathrm{RI}=48.8 ; \geq 60$ years: $\mathrm{RI}=38.1)$ and type of delivery system $(<60$ years: $R I=24.9 ; \geq 60$ years: $R I=28.3$ ) were found to be the most important across age groups. The magnitude of the RI and rank ordering of RI values were consistent across age groups (all $P=$ nonsignificant). 


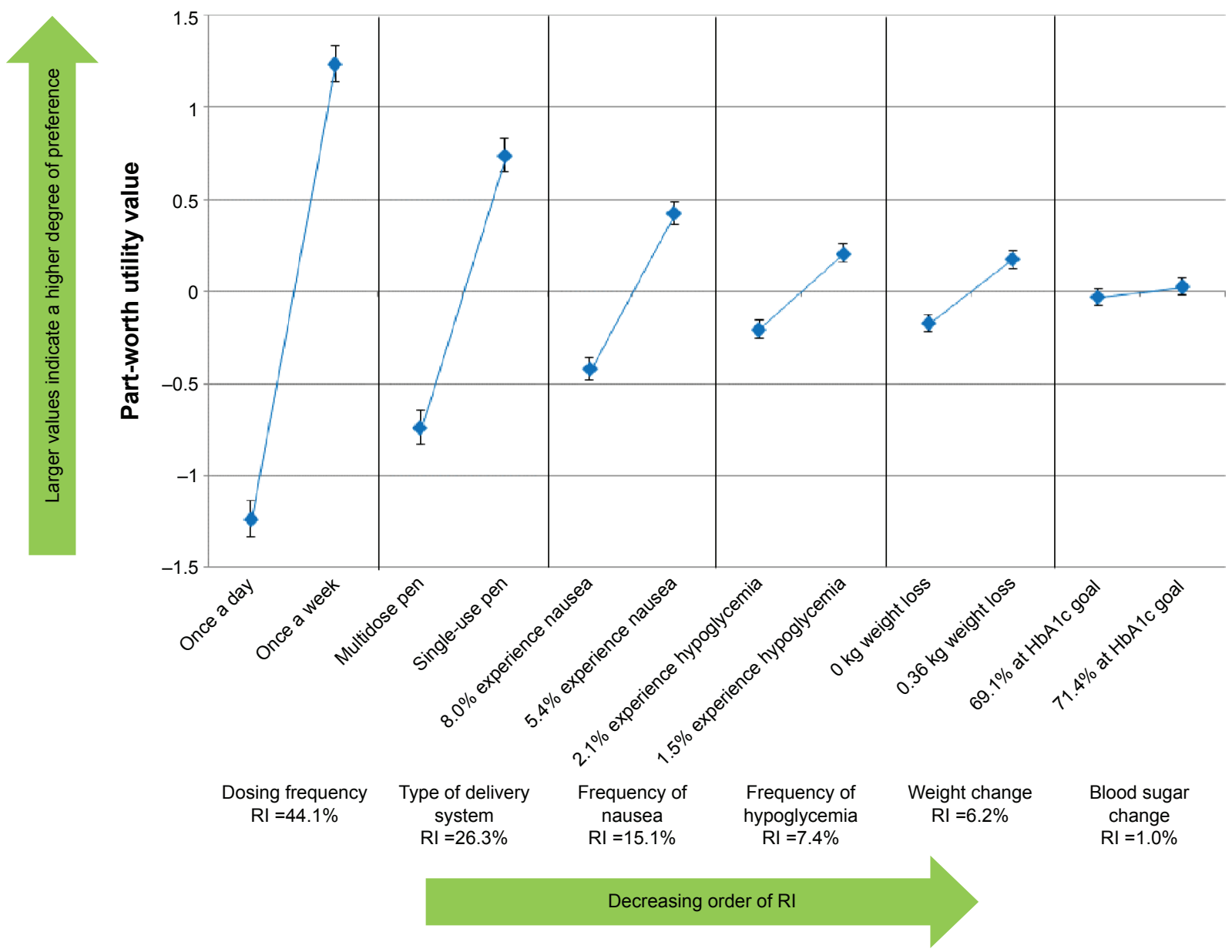

Figure I Relative importance of attributes in overall sample.

Abbreviations: $\mathrm{RI}$, relative importance; $\mathrm{HbAlc}$, hemoglobin $\mathrm{Alc}$.

Although both older and younger participants preferred once a week versus once a day dosing frequency, this preference was significantly stronger among younger (ie, $<60$ years) participants $(P<0.05)$.

\section{Preferences for dulaglutide versus liraglutide profiles}

One of the ten medication choice pairs in the DCE presented the medication profiles representing dulaglutide and liraglutide, respectively. This choice pair was used to directly examine the participants' preferences for the dulaglutide and liraglutide profiles, specifically, and was not used in the estimation of the DCE results. The large majority of participants preferred the dulaglutide profile compared to the liraglutide profile $(94.5 \%$ vs $5.5 \% ; P<0.0001)$. This preference for the dulaglutide over the liraglutide profile did not differ significantly across sex or age subgroups.

\section{Willingness to take and self-inject T2DM treatments}

Prior to completing the DCE task, participants were asked about their willingness to take an injectable diabetes medication for each dose. Only $1.1 \%$ and $0.6 \%$ indicated they would be "somewhat willing" or "very willing", respectively, while $58.2 \%$ and $31.3 \%$ indicated they would be "not willing" or "somewhat not willing", respectively. The remaining participants were neutral.

Following completion of the DCE task (including watching the videos and completing the survey), participants were significantly more willing to take a medication represented by the dulaglutide profile compared with the liraglutide profile $(P<0.0001$; Table 4$)$. Many more participants were somewhat willing $(35.2 \%)$ or very willing (7.7\%) to take a medication described by the dulaglutide profile. In contrast, only $4.4 \%$ were somewhat willing and no participants $(0.0 \%)$ were very willing to take a medication with the liraglutide profile.

\section{Discussion}

This study is the first known DCE study in Japanese patients with diabetes. In this study, Japanese T2DM patients' preferences for attributes and levels representing the actual characteristics of two specific GLP-1 RA were elicited. 


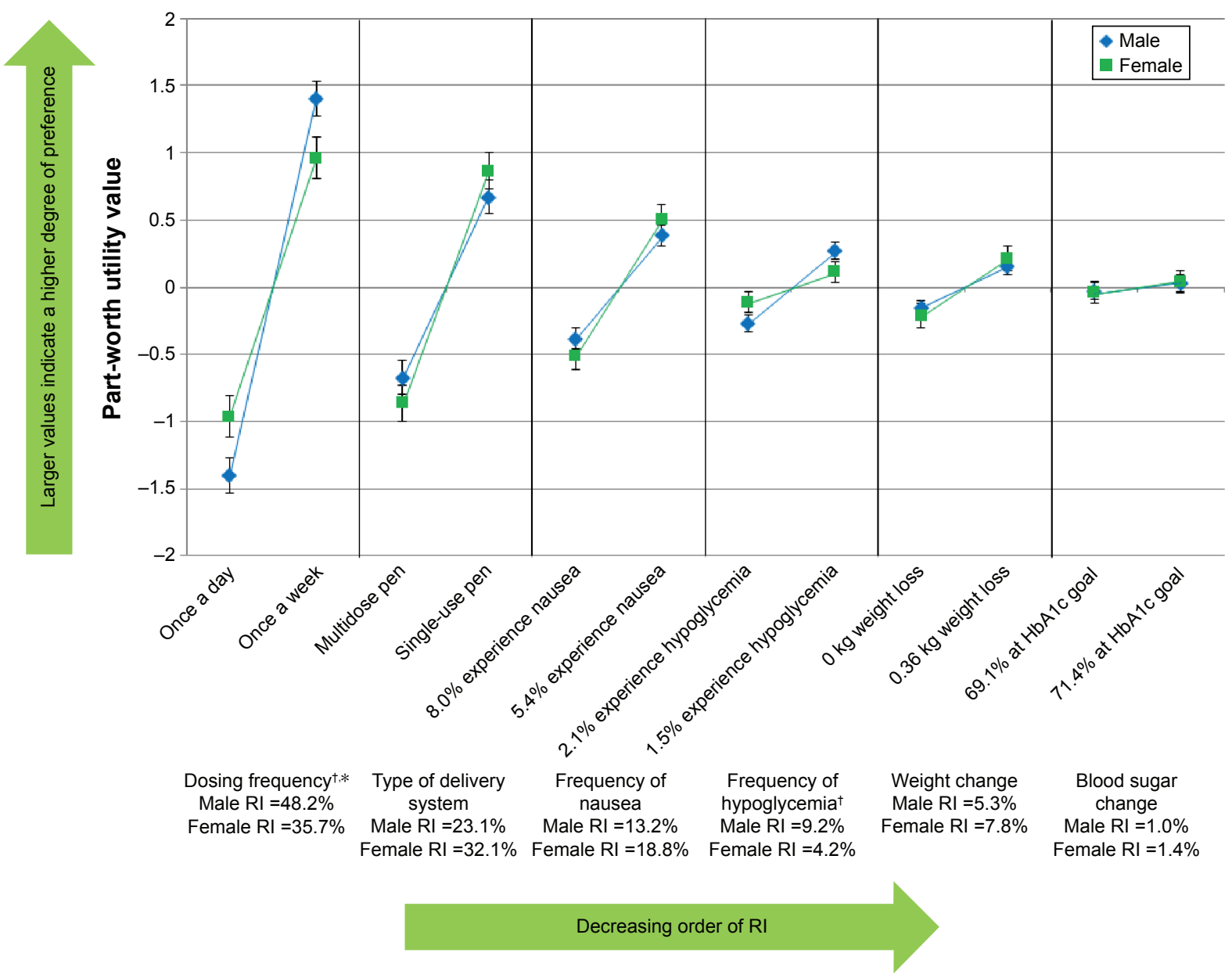

Figure 2 Relative importance of attributes by sex.

Notes: *Statistically significant difference between sexes in preference for levels of the attribute $(P<0.05)$. ${ }^{\dagger}$ Statistically significant difference in the RI of each attribute across $\operatorname{sex}(P<0.000$ I).

Abbreviations: RI, relative importance; HbAlc, hemoglobin Alc.

The study design and attribute levels were informed by a specific medication comparison based on a head-to-head clinical trial. As such, the DCE represented a real-life treatment context where the quantitative attributes related to clinical efficacy and side effect profile are not remarkably different between medication options. With both treatment options having highly similar efficacy and side effect profiles, other features that may be more qualitative in nature such as dosing frequency and type of delivery system assumed a greater role in influencing patients' preferences.

The results from the DCE of this study identified dosing frequency and type of delivery system as the two most important attributes influencing patient's preferences in the specific context of this study. This demonstrates that patients place greater value on nonclinical factors related to treatment convenience and ease of administration when medications are similar on clinical outcomes. While these results are unlike those from prior studies of T2DM patients' preferences where frequency of hypoglycemia and HbAlc reductions were generally of greatest importance to patients, ${ }^{8-10}$ those studies included broad comparisons of attribute levels that represented the features available across several classes of medications. Results from these types of studies may not be generalizable to specific medication comparisons.

The results of this study were also similar to those of the UK study upon which it was modeled. ${ }^{12}$ In both studies, dosing frequency, type of delivery system, and frequency of nausea were the top three most important attributes, in rank order, although numerically, type of delivery system had a higher RI among UK patients (Japan $26.3 \%$ vs UK $35.5 \%$ ) and frequency of nausea had a slightly higher RI among Japanese patients (Japan 15.1\% vs UK 10.4\%). Small differences in RI and rank order for the other three attributes were observed, although all three were of relatively minor importance in both studies. In both studies, direct preference for profiles representing dulaglutide or liraglutide was 

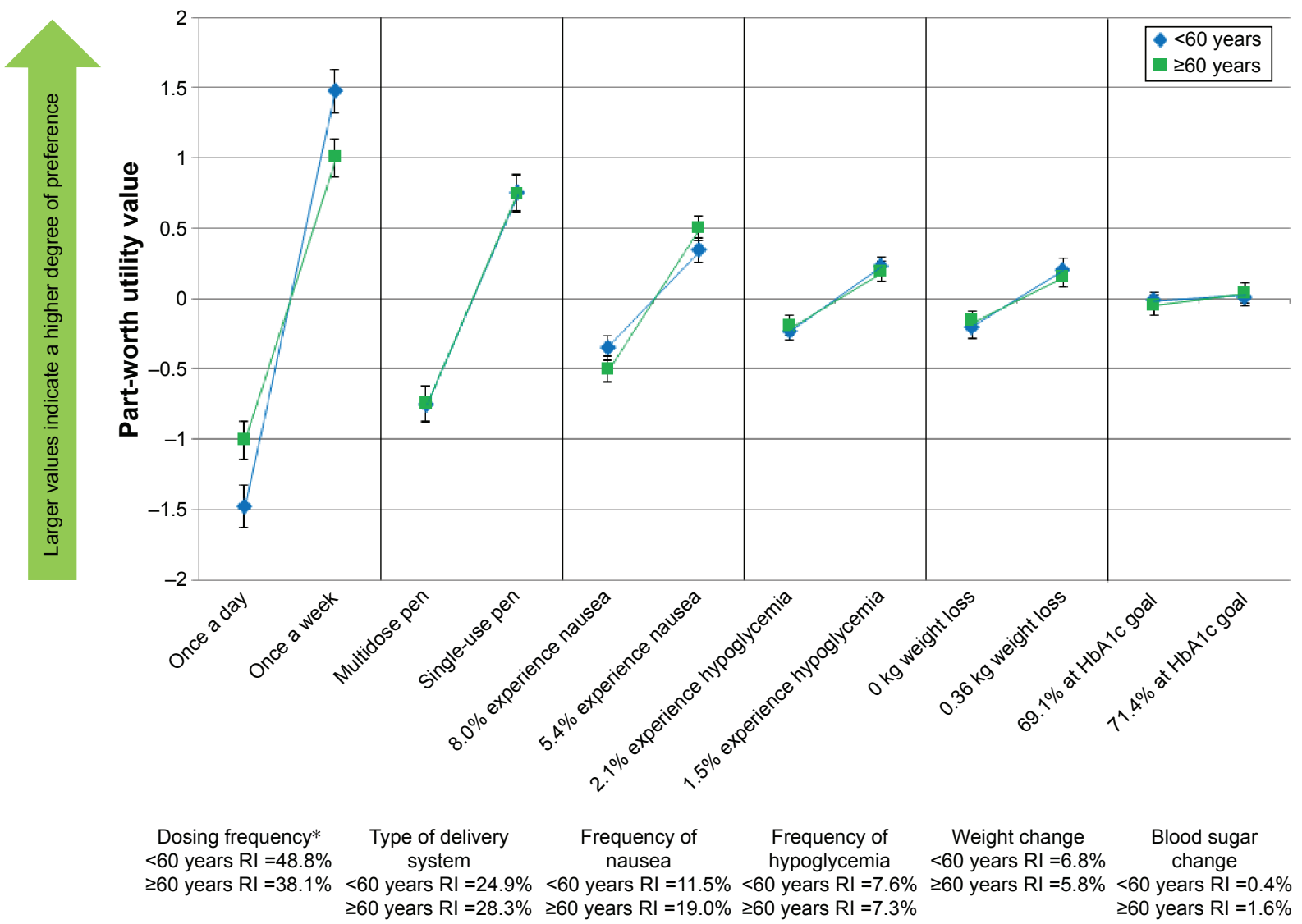

Decreasing order of RI

Figure 3 Relative importance of attributes by age group ( $<60$ years vs $\geq 60$ years).

Note: *Statistically significant difference between age groups in preference for levels of the attribute $(P<0.05)$.

Abbreviations: RI, relative importance; HbAlc, hemoglobin Alc.

overwhelmingly in favor of dulaglutide, although a greater proportion of Japanese participants than UK participants preferred the dulaglutide profile over the liraglutide profile (Japan $94.5 \%$ vs UK $83.1 \%$ ). Poststudy willingness to take the medication represented by the dulaglutide and liraglutide medication profiles also differed markedly between the two studies, with Japanese participants less willing to take either of the described medications compared to their UK counterparts. It was also remarkable the extent to which

Table 4 Patients' poststudy willingness to take medications described by the dulaglutide and liraglutide medication profiles $(\mathrm{N}=182)$

\begin{tabular}{lll}
\hline Willingness & Dulaglutide profile & Liraglutide profile \\
\hline Not willing & $2 \mathrm{I}(1 \mathrm{I} .54 \%)$ & $76(4 \mathrm{I} .76 \%)$ \\
Somewhat not willing & $48(26.37 \%)$ & $78(42.86 \%)$ \\
Neutral & $35(19.23 \%)$ & $20(10.99 \%)$ \\
Somewhat willing & $64(35.16 \%)$ & $8(4.40 \%)$ \\
Very willing & $14(7.69 \%)$ & $0(0.00 \%)$ \\
\hline
\end{tabular}

Japanese patients were unwilling to take injectable therapies at the beginning of the study (89.5\%), notably higher than those who reported being unwilling to do so at the beginning of the UK study (38.7\%). ${ }^{12}$ The Japanese patients' willingness to take injectable therapy did increase notably after injectable therapy was explained during the study. Finally, another interesting finding was that all of the Japanese participants knew their current $\mathrm{HbA} 1 \mathrm{c}$ level. In contrast, 28.0\% of participants in the previous UK study indicated that they did not know their current $\mathrm{HbAlc}$ level, and in another previous DCE, $25.7 \%$ of German participants with T2DM also reported that they did not know their current $\mathrm{HbAlc}$ level..$^{20}$ This finding may be due to cross-national differences in the frequency with which Japanese patients visit their doctors for their T2DM in contrast to other countries, making them more familiar with their HbA1c levels. ${ }^{21}$

In this study, with a very specific medication comparison dictating the design of the DCE, dosing frequency and type 
of delivery system were of greatest importance to patients. The overall results were remarkably consistent with those of the previous study in a UK T2DM population, ${ }^{12}$ especially in terms of the top three most important attributes, the direction of patients' willingness to inject medication, and the direction of patients' preferences for the dulaglutide medication profile compared to that of liraglutide. However, comparing both the Japanese and UK studies, small differences were observed in the study results. In addition to the differences in the rank order of the three less important attributes, the direct preference for the dulaglutide profile was higher in the Japan study versus the UK study. Further, almost twice as many participants in the Japan study were not willing to take a medication with the liraglutide profile compared to the UK study. There may be several reasons for these differences. First, while the attributes included in both DCEs were identical, the levels were determined using results from country-specific clinical trials, and the instructions for use of each treatment were also country specific. As a result, the magnitude of differences between attribute levels differed, which may have influenced patient preferences when making trade-offs between treatment options. For the purposes of comparison, Table 5 shows the attribute levels included in both the prior UK and the current Japanese studies. Based on the results of the respective clinical trials, ${ }^{13,22}$ these attributes and levels are identical or highly similar for some attributes (ie, dosing frequency and $\mathrm{HbA} 1 \mathrm{c}$ reduction) but were more disparate for other attributes (eg, frequency of nausea, weight change, and hypoglycemia) consistent with the results of the trials. Second, in Japan, recruitment was conducted by advertising to members of a patient database, while in the UK, recruitment was conducted among the general public through newspaper advertisements. These two study populations may thus differ in unobserved characteristics that may influence their likelihood to become a member of a patient database, where members are recruited for various clinical studies, which in turn may influence their preferences for T2DM treatment features. Finally, the influence of cultural factors on patients' beliefs and behaviors toward management of diabetes has been well documented. ${ }^{23}$ Cultural differences between Japan and the UK for perceptions of, and attitudes toward, attributes of diabetes treatments may play a role in influencing differences in patient preferences for features of GLP-1 RA, as demonstrated in these studies.

This study is not without its limitations. As with all DCEs, these findings must be interpreted within the context of the included attributes and levels. As a result, while this

Table 5 Comparison of attributes and levels for the UK and Japanese discrete choice experiments

\begin{tabular}{|c|c|c|}
\hline Attributes & Levels for Japanese Study & Levels for Prior UK Study \\
\hline Dosing frequency & $\begin{array}{l}\text { - Once a week (52 times per year). }{ }^{\mathrm{a}} \\
\text { - Once a day (365 times per year). }\end{array}$ & $\begin{array}{l}\text { - Once a week (52 times per year). }{ }^{\mathrm{a}} \\
\text { - Once a day (365 times per year). }\end{array}$ \\
\hline $\begin{array}{l}\text { Blood sugar } \\
(\mathrm{HbAIc}) \text { change }\end{array}$ & $\begin{array}{l}\text { - } 71.4 \% \text { of patients taking the medication reach their } \\
\text { desired blood sugar ( } \mathrm{HbAIC} \text { ) goals of }<7 \% \text {. }^{\mathrm{a}} \\
\text { - } 69.1 \% \text { of patients taking the medication reach their } \\
\text { desired blood sugar (HbAIc) goals of }<7 \% \text {. }^{\mathrm{b}}\end{array}$ & $\begin{array}{l}\text { - } 68.3 \% \text { of patients taking the medication reach their } \\
\text { desired blood sugar (HbAlc) goals of }<7 \% .^{a} \\
\text { - } 67.9 \% \text { of patients taking the medication reach their } \\
\text { desired blood sugar (HbAlc) goals of }<7 \% .^{\text {b }}\end{array}$ \\
\hline Weight change & $\begin{array}{l}\text { - On average, patients experience a very small amount } \\
\text { of weight loss }(-0.36 \mathrm{~kg}) .^{\mathrm{b}} \\
\text { - On average, patients do not experience any change } \\
\text { in their body weight. }\end{array}$ & $\begin{array}{l}\text { - Patients experience an average weight loss of } \\
3.6 \mathrm{l} \mathrm{kg} \text { after the first } 6 \text { months of medication use. } \\
\text { - Patients experience an average weight loss of } \\
2.90 \mathrm{~kg} \text { after the first } 6 \text { months of medication use. }{ }^{\text {. }}\end{array}$ \\
\hline $\begin{array}{l}\text { Type of delivery } \\
\text { system }\end{array}$ & $\begin{array}{l}\text { - Single-use prefilled pen ready for injection. }{ }^{\mathrm{a}} \\
\text { - Multidose prefilled pen, used with disposable injection } \\
\text { needles, dosage selection required. }{ }^{b}\end{array}$ & $\begin{array}{l}\text { - Single-use prefilled pen ready for injection. }{ }^{\text {a }} \\
\text { - Multidose prefilled pen, used with disposable } \\
\text { injection needles, dosage selection required. }{ }^{b}\end{array}$ \\
\hline $\begin{array}{l}\text { Frequency of } \\
\text { nausea }\end{array}$ & $\begin{array}{l}\text { - } 5.4 \% \text { of patients experience nausea anytime in the first } \\
6 \text { months of treatment. } \\
\text { - } 8.0 \% \text { of patients experience nausea anytime in the first } \\
6 \text { months of treatment. }\end{array}$ & $\begin{array}{l}\text { - } 20.4 \% \text { of patients experience nausea anytime in } \\
\text { the first } 6 \text { months of treatment. } \\
\text { - } 18.0 \% \text { of patients experience nausea anytime in } \\
\text { the first } 6 \text { months of treatment. }\end{array}$ \\
\hline $\begin{array}{l}\text { Frequency of low } \\
\text { blood sugar event } \\
\text { (hypoglycemia) }\end{array}$ & $\begin{array}{l}\text { - } 1.5 \% \text { of patients experience a low blood sugar } \\
\text { (hypoglycemic) event in the first } 6 \text { months of treatment. } \\
\text { - } 2.1 \% \text { of patients experience a low blood sugar } \\
\text { (hypoglycemic) event in the first } 6 \text { months of treatment. }{ }^{\text {a }}\end{array}$ & $\begin{array}{l}\text { - On average a patient would experience one low } \\
\text { blood sugar (hypoglycemia) event every } 2 \text { years. } \\
\text { - On average a patient would experience one low } \\
\text { blood sugar (hypoglycemia) event every } 3 \text { years. }\end{array}$ \\
\hline
\end{tabular}

Notes: aLevel representing dulaglutide. 'Level representing liraglutide. The results of clinical trials conducted in Japan ${ }^{13}$ and the UK ${ }^{22}$ were used to generate country-specific attribute levels for each study, respectively.

Abbreviations: SE, standard error; HbAlc, hemoglobin Alc. 
methodology may be commonly used to estimate preferences for attributes of health care services, the elicited preferences may not always reflect patients' actual real-life medication decisions, as other attributes may also come into play. Finally, the sample population was predominantly male. However, this is representative of the prevalence of diabetes by sex in Japan, which allows for the generalizability of the results to the Japanese population.

\section{Conclusion}

In this study, Japanese T2DM patients were presented with attributes and corresponding levels representing the actual characteristics of two available GLP-1 RA treatment options, dulaglutide and liraglutide. The most important factors influencing patient preferences for such treatments were dosing frequency, type of delivery system, and frequency of nausea. This was highly similar to the findings from a previous study among a UK T2DM population using a similar study design. The results of this study may help Japanese treatment providers better understand patients' preferences for GLP-1 RA. The similarity of these findings to those of the UK study also provide information about patients' preferences that may then be generalizable to the broader T2DM patient population, providing guidance for patient-clinician treatment discussions.

\section{Acknowledgments}

The authors would like to thank Fritz Hamme for his assistance in the preparation of this manuscript and Yuko Imaizumi of CROee Inc. and Eriko Takezawa of CTS for the project management of the in-person survey. This research was funded by Eli Lilly and Company.

\section{Disclosure}

HLG, EDB, and JLP are full-time employees of Evidera. KSB and SMB are full-time employees and minor shareholders of Eli Lilly and Company. SS is a full-time employee of Eli Lilly Japan. The authors report no other conflicts of interest in this work.

\section{References}

1. International Diabetes Foundation [homepage on the Internet]. IDF Diabetes Atlas - 7th Edition. 2015. Available from: http://www.diabetesatlas.org. Accessed February 1, 2016.

2. Japan Diabetes Society [webpage on the Internet]. Treatment Guide for Diabetes, 2012-2013. Available from: http://www.jds.or.jp/modules/en/ index.php?content_id=1. Accessed February 1, 2016.

3. Trujillo JM, Nuffer W, Ellis SL. GLP-1 receptor agonists: a review of head-to-head clinical studies. Ther Adv Endocrinol Metab. 2015;6(1): $19-28$.
4. Pharmaceuticals and Medical Devices Agency [webpage on the Internet]. New Drugs. Available from: http://www.pmda.go.jp/english/review-services/reviews/approved-information/drugs/0002.html. Accessed January 26, 2016.

5. Okumura K, Inoue H, Yasaka M, et al. Comparing patient and physician risk tolerance for bleeding events associated with anticoagulants in atrial fibrillation-evidence from the United States and Japan. Value Health Reg Issues. 2015;6:65-72.

6. Kawaguchi T, Azuma K, Yamaguchi T, et al. Preferences for pharmacist counselling in patients with breast cancer: a discrete choice experiment. Biol Pharm Bull. 2014;37(11):1795-1802.

7. Kimoto Y, Murata T, Lloyd AJ, Nafees B. Discrete choice experiment to estimate preference and willingness to pay on intermittent urinary catheters in patients with voiding dysfunction from neurogenic bladder. Ther Res. 2015;36(7):683-697.

8. Gelhorn HL, Stringer SM, Brooks A, et al. Preferences for medication attributes among patients with type 2 diabetes mellitus in the UK. Diabetes Obes Metab. 2013;15(9):802-809.

9. Hauber AB, Tunceli K, Yang JC, et al. A survey of patient preferences for oral antihyperglycemic therapy in patients with type 2 diabetes mellitus. Diabetes Ther. 2015;6(1):75-84.

10. Mühlbacher A, Bethge S. What matters in type 2 diabetes mellitus oral treatment? A discrete choice experiment to evaluate patient preferences. Eur J Health Econ. Epub 2015 Dec 18.

11. Hauber AB, Nguyen H, Posner J, Kalsekar I, Ruggles J. A discretechoice experiment to quantify patient preferences for frequency of glucagon-like peptide-1 receptor agonist injections in the treatment of type 2 diabetes. Curr Med Res Opin. 2016;32(2):251-262.

12. Gelhorn HL, Poon JL, Davies EW, Paczkowski R, Curtis SE, Boye KS. Evaluating preferences for profiles of GLP-1 receptor agonists among injection-naive type 2 diabetes patients in the UK. Patient Prefer Adherence. 2015;9:1611-1622.

13. Miyagawa J, Odawara M, Takamura T, Iwamoto N, Takita Y, Imaoka T. Once-weekly glucagon-like peptide-1 receptor agonist dulaglutide is non-inferior to once-daily liraglutide and superior to placebo in Japanese patients with type 2 diabetes: a 26-week randomized phase III study. Diabetes Obes Metab. 2015;17(10):974-983.

14. Polster M, Zanutto E, McDonald S, Conner C, Hammer M. A comparison of preferences for two GLP-1 products - liraglutide and exenatide - for the treatment of type 2 diabetes. J Med Econ. 2010;13(4):655-661.

15. Marshall D, Bridges JF, Hauber B, et al. Conjoint analysis applications in health - how are studies being designed and reported?: an update on current practice in the published literature between 2005 and 2008 . Patient. 2010;3(4):249-256.

16. Kuhfeld WF [webpage on the Internet]. Marketing Research Methods in SAS: Experimental Design, Choice, Conjoint, and Graphical Techniques. SAS 9.2 Edition. MR-2010. 2010. Available from: http://support. sas.com/techsup/technote/mr2010.pdf. Accessed April 13, 2015.

17. Orme B. Getting Started with Conjoint Analysis: Strategies for Product Design and Pricing Research. Madison, WI: Research Publishers, LLC; 2005.

18. Lilly Diabetes [webpage on the Internet]. Instructions for Use: Trulicity $^{\circledast} 0.75 \mathrm{mg}$ Single-Use Pre-Filled Pen Ateos ${ }^{\circledR}$ (Dulaglutide). Available from: https://www.diabetes.co.jp/usage/trulicity.aspx. Accessed February 1, 2016.

19. Novo Nordisk [webpage on the Internet]. Instructions for Use: Victoza $^{\circledR} 6 \mathrm{mg} / \mathrm{mL}$ Solution for Injection in Pre-Filled Pen (Liraglutide). Available from: http://www.novonordiskpro.jp/content/dam/nnpro/ japan/ja/products/victoza/documents/victoza_use_correctly.pdf. Accessed February 1, 2016.

20. Gelhorn HL, Stringer SM, Reinders S, Schreeb KH. German patients' preferences for attributes of type 2 diabetes medications. Paper presented at: The ISPOR 17th Annual European Congress; November 8-12, 2014; Amsterdam, the Netherlands. 
21. Xie J, Suzuki S, Cos X, Hassoun A, Matsuba I, Polinski JM. Crossnational variation in physicians' characteristics and their goals for patients taking insulin: a global perspective from the MOSAIc study. Paper presented at: American Diabetes Association 74th Annual Scientific Session; June 13-17, 2014; San Francisco, CA.

22. Dungan KM, Povedano ST, Forst T, et al. Efficacy and safety of once weekly dulaglutide versus once daily liraglutide in type 2 diabetes (AWARD-6). Paper presented at: American Diabetes Association's 74th Scientific Sessions; June 13-17, 2014; San Francisco, CA.
23. Nam S, Chesla C, Stotts NA, Kroon L, Janson SL. Barriers to diabetes management: patient and provider factors. Diabetes Res Clin Pract. 2011;93(1):1-9.

\section{Publish your work in this journal}

Patient Preference and Adherence is an international, peer-reviewed, open access journal that focuses on the growing importance of patient preference and adherence throughout the therapeutic continuum. Patient satisfaction, acceptability, quality of life, compliance, persistence and their role in developing new therapeutic modalities and compounds to optimize clinical outcomes for existing disease states are major areas of interest for the journal. This journal has been accepted for indexing on PubMed Central. The manuscript management system is completely online and includes a very quick and fair peer-review system, which is all easy to use. Visit http://www. dovepress.com/testimonials.php to read real quotes from published authors.

Submit your manuscript here: http://www.dovepress.com/patient-preference-and-adherence-journal 